\title{
A novel FISH assay for SS18-SSX fusion type in synovial sarcoma
}

\author{
Cecilia Surace ${ }^{1,2}$, Ioannis Panagopoulos ${ }^{1}$, Eva Pålsson $^{1}$, Mariano Rocchi $^{2}$, Nils Mandahl ${ }^{1}$ \\ and Fredrik Mertens ${ }^{1}$ \\ ${ }^{1}$ Department of Clinical Genetics, Lund University Hospital, Lund, Sweden and ${ }^{2}$ DAPEG, Section of Genetics, \\ University of Bari, Bari, Italy
}

\begin{abstract}
Synovial sarcoma is a morphologically, clinically and genetically distinct entity that accounts for $\mathbf{5 - 1 0 \%}$ of all soft tissue sarcomas. The $t(X ; 18)(p 11.2 ; q 11.2)$ is the cytogenetic hallmark of synovial sarcoma and is present in more than $90 \%$ of the cases. It produces three types of fusion gene formed in part by SS18 from chromosome 18 and by SSX1, SSX2 or, rarely, SSX4 from the X chromosome. The SS18-SSX fusions do not seem to occur in other tumor types, and it has been shown that in synovial sarcoma a clear correlation exists between the type of fusion gene and histologic subtype and, more importantly, clinical outcome. Previous analyses regarding the type of fusion genes have been based on PCR amplification of the fusion transcript, requiring access to goodquality RNA. In order to obtain an alternative tool to diagnose and follow this malignancy, we developed a fluorescence in situ hybridization (FISH) assay that could distinguish between the two most common fusion genes, that is, SS18-SSX1 and SS18-SSX2. The specificity of the selected bacterial artificial chromosome clones used in the detection of these fusion genes, as well as the sensitivity of the analysis in metaphase and interphase cells, was examined in a series of $\mathbf{2 8}$ synovial sarcoma samples with known fusion gene status. In all samples, the type of fusion was correctly identified by FISH. Thus, the assay described here should be useful for clarifying unresolved chromosome markers and for identifying fusion gene status in samples from which RNA of sufficient quality for PCR could not be extracted.
\end{abstract}

Laboratory Investigation (2004) 84, 1185-1192, advance online publication, 21 June 2004; doi:10.1038/labinvest.3700142

Keywords: BAC; FISH; SSX; SS18; synovial sarcoma

Synovial sarcoma accounts for $5-10 \%$ of all soft tissue sarcomas. ${ }^{1}$ It is most prevalent in adolescents and young adults between 15 and 40 years of age, occurs predominantly in males, and is often found in juxta-articular locations, particularly in the area of the knee. However, synovial sarcoma occasionally occurs in areas with no apparent relationship to synovial structures, such as the head and neck region and the trunk.

Histologically, synovial sarcoma may be subdivided into four variants, the biphasic and the monophasic subtypes being the most common. Biphasic synovial sarcoma is characterized by epithelial and spindle cell components in varying proportions, whereas the monophasic type has a spindle cell component alone. Monophasic epithelial and poorly differentiated subtypes have also been discerned, but are much less common. Poorly

Correspondence: Dr F Mertens MD, PhD, Department of Clinical Genetics, Lund University Hospital, Lund, SE-221 85, Sweden.

E-mail: Fredrik.Mertens@klingen.lu.se

Received 19 December 2003; revised 30 April 2004; accepted 9 May 2004; published online 21 June 2004 differentiated synovial sarcoma, in particular, poses a diagnostic problem, as it is difficult to distinguish from other round cell sarcomas. Thus, molecular genetic techniques may be useful in reaching a correct diagnosis. ${ }^{2}$

The $\mathrm{t}(\mathrm{X} ; 18)(\mathrm{p} 11.2 ; \mathrm{q} 11.2)$ is the cytogenetic hallmark of synovial sarcoma, being present in more than $90 \%$ of all the cases reviewed in the literature. $^{3-5}$ It produces three types of fusion gene formed in part by $S S 18$ (also known as $S Y T$ ) from chromosome 18 and by $S S X 1, S S X 2$ or $S S X 4$ from the X chromosome. ${ }^{6}$ The $S S 18-S S X$ fusion gene is always retained during tumor progression and is transcribed from the der(X) chromosome. In the oncogenic fusion protein, the eight carboxy (C)-terminal amino acids of SS18 are replaced with the last 78 amino acids of SSX. ${ }^{7}$

It has previously been shown that a correlation exists between histologic subtype and type of fusion gene, with biphasic and monophasic histologies being more characteristic of the SS18-SSX1 and SS18-SSX2 fusions, respectively. ${ }^{8}$ Furthermore, patients with SS18-SSX1 fusion genes have a worse clinical outcome than patients with 
SS18-SSX2-positive tumors. $^{9}$ The SS18-SSX4 fusion gene is much less frequent than the other two types, making up less than $1 \%$ of the cases, and nothing is known about its clinical impact. ${ }^{9,10}$

Although the different SS18-SSX fusion genes, as well as the variant reported in a single case, ${ }^{11}$ are readily detected by reverse transcriptasepolymerase chain reaction (RT-PCR), sufficient amounts of good-quality RNA may not always be available. Thus, we wanted to develop a fluorescence in situ hybridization (FISH) assay that could distinguish between the two most common fusion genes, that is, $S S 18-S S X 1$ and SS18-SSX2. For this purpose, we identified bacterial artificial chromosome (BAC) clones, specific for the $S S X 1, S S X 2$ and $S S 18$ genes, which should allow the detection of synovial sarcoma fusion genes by FISH not only in metaphase cells, but also in interphase cells. The specificity of these probes, as well as the sensitivity of the analysis, was examined in a series of 28 synovial sarcoma samples with known fusion gene status.

\section{Materials and methods}

A total of 28 samples from 21 patients with synovial sarcoma were processed for FISH investigations. From three patients, multiple (2-5) samples were investigated. Culturing, harvesting of tumor cells and chromosome banding were performed as previously described. ${ }^{12}$ The karyotypes were described according to the International System for Human Cytogenetic Nomenclature. ${ }^{13}$

All the samples were analyzed beforehand by RT-PCR, as reported elsewhere, ${ }^{14}$ in order to detect the type of fusion gene (SS18-SSX1 or SS18-SSX2). The clinical, cytogenetic and molecular features are listed in Table 1.

FISH was carried out as described. ${ }^{15}$ The following BAC clones were used as probes in the FISH experiments: RP11-38O23 (Accession No. AL356464; map position 47022510-47096260), RP11-552E4 (AL683817; 47096261-47173328) and RP11-344N17 (AL606490; 47173329-47311004) as a pool for the SSX1 gene; RP11-552J9 (AL450023; 51569622-51753153) and RP13-77O11 (AL445236; 51753154-51900350) as a pool for the SSX2 gene; and RP11-737G21 (AC027229; 21729417-21788220), RP11-786F14 (AC091021; 21788221-21981898) and RP11-399L5 (AC016839; 21981899-22097735) as a pool for the $S S 18$ gene. The clones belong to the RPCI library (http://www.chori.org/bacpac/) and were obtained from Resources for Molecular Cytogenetics (http://www.biologia.uniba.it/rmc/). The UCSC database (University of California Santa Cruz, http://genome.ucsc.edu/index.html, April and July 2003 releases) was queried for the location of the clones. The BAC clones RP11-552E4 and RP11344 N17 were selected and used previously by Storlazzi et $a l^{11}$ as a pool for the whole cluster of $S S X$ genes, on the basis of the June 2002 release of the UCSC database. Probes for the SSX1 gene were directly labeled with Cy3-dUTP (Amersham Biosciences, UK); probes for the SSX2 gene were indirectly labeled with biotin-dUTP (Enzo, Roche, Germany) and detected with streptavidin-diethylaminocoumarin (Roche, Germany and Molecular Probes, The Netherlands); probes for the SS18 gene were directly labeled with Fluor-X-dCTP (Amersham Biosciences, UK). The labeling of all the clones was performed by use of Amersham's Mega Prime kit (Amersham Biosciences, UK). The hybridizations were performed on metaphase and interphase cells from short-term cultures, and were analyzed with the aid of the Chromofluor System (Applied Imaging, Newcastle, UK).

In the present FISH analysis, a pool of BAC probes mentioned before spanning the SSX1and SSX4 genes was cohybridized with a pool of BACs covering the entire $S S X 2$ gene and with a pool of BAC probes specific for the $S S 18$ gene in order to recognize, in a single hybridization experiment, if an SS18-SSX1 or an SS18-SSX2 fusion gene was formed. These clones were selected with the aim of covering more than the entire length of the involved genes. Hence, wherever the breakpoints are located in the $S S X 1, S S X 2$ and $S S 18$ genes, the two parts originating from the splitting of the pools of BAC probes would always be large enough to be detected by FISH. This is particularly important for revealing fusion genes in cases with unusual breakpoints or with more complex translocations, for example, three-way translocations.

All the BAC clones were tested one by one on metaphase and interphase cells of healthy donors in order to analyze the strength of the signals, the lack of crosshybridization or chimeric signals and the absence of background. Then, the pools of clones were also cohybridized on normal male cells with the purpose of evaluating the pattern of the FISH signals and the efficiency of the probes when used together. The results of the latter experiment are shown in Figure 1a.

Then, 28 samples of synovial sarcoma were analyzed. These samples had been selected so as to include both $S S X 1$ - and $S S X 2$-positive cases, as well as one of the very rare cases with the SS18SSX4 fusion gene, and to represent both cytogenetically simple and complex variants of the $t(X ; 18)$. All signal observations were performed in a blinded manner, without knowing the results of the karyotypic or RT-PCR analyses. A total of 10 metaphases and 50 interphase nuclei for each case were counted. Signals in overlapping and incomplete nuclei were not recorded. A schematic illustration of the expected FISH signals in normal male and female nuclei and in nuclei carrying the translocation $t(X ; 18)(p 11.2 ; q 11.2)$, together with the ideograms of the rearranged chromosomes, is shown in Figure 2. 
Table 1 Cytogenetic, PCR and FISH findings in 28 synovial sarcomas

\begin{tabular}{|c|c|c|c|c|c|c|c|c|c|}
\hline \multirow[t]{3}{*}{ Sample ${ }^{\text {a }}$} & \multirow[t]{3}{*}{ Sex } & \multirow[t]{3}{*}{$P C R^{\mathrm{b}}$} & \multirow[t]{3}{*}{ Karyotype $^{\mathrm{c}}$} & \multicolumn{6}{|c|}{$F I S H^{\mathrm{d}}$} \\
\hline & & & & \multicolumn{2}{|c|}{$S S X 1 \%$} & \multicolumn{2}{|c|}{$S S X 2 \%$} & \multicolumn{2}{|c|}{ Other $\%$} \\
\hline & & & & $M$ & $I$ & $M$ & $I$ & $M$ & $I$ \\
\hline 1a $\mathrm{P}$ & $\mathrm{F}$ & $S S X 2$ & 44,-X,t(X;18)(p11;q11),add(5)(p11),-15/44,idem,t(3;12)(p23;q12) & 0 & 0 & 100 & 76 & 0 & 24 \\
\hline $1 \mathrm{~b} \mathrm{R}$ & $\mathrm{F}$ & SSX2 & $44,-\mathrm{X}, \mathrm{t}(\mathrm{X} ; 18)(\mathrm{p} 11 ; \mathrm{q} 11), \mathrm{t}(3 ; 12)(\mathrm{p} 23 ; \mathrm{q} 12), \mathrm{add}(5)(\mathrm{p} 11),-15 / 44, \mathrm{idem},-\mathrm{t}(3 ; 12),+\mathrm{r}$ & 0 & 0 & 70 & 32 & 30 & 68 \\
\hline 1c M & $\mathrm{F}$ & SSX2 & $40-49,-\mathrm{X}, \mathrm{t}(\mathrm{X} ; 18)(\mathrm{p} 11 ; \mathrm{q} 11), \mathrm{t}(3 ; 12)(\mathrm{p} 23 ; \mathrm{q} 12)$, add(5)(p11),+1-3r,inc & 0 & 0 & 100 & 76 & 0 & 24 \\
\hline $1 \mathrm{~d} R$ & $\mathrm{~F}$ & SSX2 & $44,-\mathrm{X}, \mathrm{t}(\mathrm{X} ; 18)(\mathrm{p} 11 ; \mathrm{q} 11), \mathrm{t}(3 ; 12)(\mathrm{p} 23 ; \mathrm{q} 12), \mathrm{add}(5)(\mathrm{p} 11),-15$ & 0 & 0 & 60 & 92 & 40 & 8 \\
\hline $1 \mathrm{e} \mathrm{M}$ & $\mathrm{F}$ & SSX2 & $44,-\mathrm{X}, \mathrm{t}(\mathrm{X} ; 18)(\mathrm{p} 11 ; \mathrm{q} 11)$, add(5)(p11),-15 & 0 & 0 & 100 & 88 & 0 & 12 \\
\hline 2a $\mathrm{M}$ & $\mathrm{M}$ & SSX1 & 44,Y,t(X;18)(p11;q11),del(1)(p12p22),del(3)(p12p25),inv(9)(p11q12)c,-11,-22 & 100 & 88 & 0 & 0 & 0 & 12 \\
\hline 2b M & M & SSX1 & $41-44$, same as above, $-4, \operatorname{add}(6)(\mathrm{q} 21),-8,-14$, add(16)(p11),+mar & 100 & 96 & 0 & 0 & 0 & 4 \\
\hline 2c M & M & $S S X 1$ & $\begin{array}{l}\text { 42-44,Y,t(X;18),del(1)(p12p22),del(1)(p22),+- } \\
\text { der(1;?)(p10;?)t(?;3)(?;q21),-2,-3,der(4)t(4;5)(q24;q13),add(5)(p14),-8,inv(9) } \\
\text { (p11q12)c,-11,add(11)(p15),-12,?del(13)(q22),-14,-15,+der(?)t(?;12)(?;- } \\
-15,+\operatorname{der}(?) t(? ; 12)(? ; q 15),+4 m a r\end{array}$ & 100 & 90 & 0 & 0 & 0 & 10 \\
\hline 3a $R$ & $\mathrm{M}$ & $S S X 1$ & $\begin{array}{l}\text { 43,Y,t(X;18)(p11;q11),del(2)(p23),dic(3;?)(p11;?),der(5)del(5)(q11q13)ins(5;?) } \\
\text { (q11;?)add(5)(p15),t(7;22)(q11;q13),-11,add(15)(q26),-18,-19,-21,+mar }\end{array}$ & 100 & 90 & 0 & 0 & 0 & 10 \\
\hline 3b M & M & SSX1 & Same as above/43,idem,t(4;13)(p14;q13)/85-86,idemx2 & 70 & 90 & 0 & 0 & 30 & 10 \\
\hline $4 \mathrm{P}$ & $\mathrm{M}$ & $S S X 1$ & $\begin{array}{l}\text { 44-46,XY,add(3)(q13),der(5)t(5;8)(p15;q13)ins(5;?)(p15;?),der(5)t(5;8) } \\
\text { (q35;q13)ins(5;?)(q35;?),-8,-9,add(9)(p24),der(10;13)(q10;q10),+del(10) } \\
\text { (q22),+add(15)(q22),-17,-17,+der(?)t(?;8)(?;q13)ins(?;5)(?;?)t(?;8)(?;q13) }\end{array}$ & 40 & 0 & 0 & 0 & 60 & 100 \\
\hline $5 \mathrm{P}$ & $\mathrm{M}$ & $S S X 2$ & $\begin{array}{l}\text { 46,Y,t(X;18)(p11;q11)/45,Y,der(X)t(X;18),del(5)(q13),der(7)t(7;8)(q11;p21), } \\
\operatorname{der}(8) \mathrm{t}(\mathrm{X} ; 8)(\mathrm{p} 11 ; \mathrm{p} 21),-10, \operatorname{ins}(14 ; ?)(\mathrm{q} 24 ; ?) \operatorname{or} \operatorname{der}(14) \mathrm{t}(5 ; 14)(\mathrm{q} 31 ; \mathrm{q} 24),- \\
\operatorname{der}(18) \mathrm{t}(\mathrm{X} ; 18)(\mathrm{p} 11 ; \mathrm{q} 11) \mathrm{t}(\mathrm{X} ; 7)(\mathrm{p} 11 ; \mathrm{q} 11)\end{array}$ & 0 & 0 & 100 & 86 & 0 & 14 \\
\hline $6 \mathrm{M}$ & $\mathrm{M}$ & $S S X 1$ & $\begin{array}{l}\text { 45,Y,t(X;18)(p11;q11),der(2)t(2;8)(q13;q21)t(2;2)(p13;q37)add(2)(q13), } \\
\text { der(8)t(2;8)(p13;q21),add(9)(q32),der(10;14)(q10;q10)/ } \\
45, \text { idem,der(6)t(1;6)(q21;q27) }\end{array}$ & 100 & 84 & 0 & 0 & 0 & 16 \\
\hline $7 \mathrm{P}$ & $\mathrm{M}$ & $S S X 2$ & $\begin{array}{l}58-59, \mathrm{Y}, \operatorname{der}(\mathrm{X}) \mathrm{t}(\mathrm{X} ; 18)(\mathrm{p} 11 ; \mathrm{q} 11) \mathrm{x} 2,+\mathrm{Y},-1, \operatorname{der}(2) \mathrm{t}(2 ; 3)(\mathrm{p} 25 ; \mathrm{q} 21),-3,-3,-4,-5, \\
-6,-10,-11,+12,-13,-13,-14,-15, \operatorname{add}(15)(\mathrm{q} 22),-16,-17,-18,-19,- \\
20,-21,+22, \operatorname{add}(22)(\mathrm{q} 13) \times 2,+\operatorname{der}(?) \mathrm{t}(? ; 1)(? ; \mathrm{q} 21),+3 \mathrm{mar}\end{array}$ & 0 & 0 & 100 & 30 & 0 & 70 \\
\hline $8 \mathrm{P}$ & M & SSX2 & $46, Y, t(X ; 18)(p 11 ; q 11), \operatorname{der}(9) t(9 ; 9)(p 21 ; q 21)$ & 0 & 0 & 100 & 84 & 0 & 16 \\
\hline $9 \mathrm{P}$ & $\mathrm{M}$ & SSX2 & $46, Y, t(X ; 18)(p 11 ; q 11)$ & 0 & 0 & 100 & 74 & 0 & 26 \\
\hline $10 \mathrm{P}$ & $\mathrm{M}$ & $S S X 2$ & $\begin{array}{l}\text { 86-87,Y,der(X)t(X;18)(p11;q11)x2,-Y,add(1)(p36),add(1)(q11),del(1)(q11), } \\
+\operatorname{der}(1) \mathrm{t}(1 ; 5)(\mathrm{p} 13 ; \mathrm{q} 13) \times 2,-2,-3, \operatorname{del}(3)(\mathrm{q} 12),-4,-5, \operatorname{add}(6)(\mathrm{q} 15),-7,-9,-10, \\
-10,-11, ? \operatorname{add}(12)(\mathrm{q} 13),-13, ?-14,-19,-19,-20,-21,-21,+2-3 \mathrm{r}, \mathrm{inc}\end{array}$ & 0 & 0 & 100 & 82 & 0 & 18 \\
\hline $11 \mathrm{P}$ & $\mathrm{M}$ & $S S X 1$ & $\begin{array}{l}\text { 43,Y,t(X;18)(p11;q11),-6,der(12)t(12;?13)(p12;q12),-13,-14,-15, } \\
\operatorname{add}(16)(q 24), \operatorname{add}(22)(\mathrm{q} 13),+\operatorname{mar}\end{array}$ & 100 & 70 & 0 & 0 & 0 & 30 \\
\hline $12 \mathrm{P}$ & $\mathrm{F}$ & $S S X 1$ & $\begin{array}{l}\text { 94-96,XX,t(X;18)(p11;q11)x2,+4,+6,+der(8;18)(q10;q10)x } 2,+9, \\
\text { add(11)(q25)x2,+12,+13,-14,-15,+17,add(17)(q23)x2,+22, } \\
+22 / 95-101, \text { idem, }+13,+17 / 95-99, \text { idem,+22/98,idem,-2,-4,+22 }\end{array}$ & 90 & 74 & 0 & 0 & 10 & 26 \\
\hline $13 \mathrm{P}$ & $\mathrm{F}$ & $S S X 4$ & $\begin{array}{l}\text { 46,X,der(X)t(X;18)(p11;q11)del(X)(q13),+der(X)t(X;18)del(X),der(5)t(5;6) } \\
\text { (q31;q21),add(6)(q13),del(12)(q22),-18 }\end{array}$ & NA & 8 & NA & 0 & NA & 92 \\
\hline $14 \mathrm{P}$ & $\mathrm{M}$ & $S S X 2$ & $46, \mathrm{Y}, \mathrm{t}(\mathrm{X} ; 16 ; 18)(\mathrm{p} 11 ; \mathrm{q} 22 ; \mathrm{q} 11), \mathrm{t}(1 ; 15)(\mathrm{q} 21 ; \mathrm{q} 24)$ & NA & 0 & NA & 72 & NA & 28 \\
\hline $15 \mathrm{P}$ & M & SSX1 & 46,Y,t(X;20;8;15;18)(p11;p13;p11;q23;q11) & 100 & 84 & 0 & 0 & 0 & 16 \\
\hline $16 \mathrm{P}$ & $\mathrm{F}$ & SSX2 & 46,X,t(X;18)(p11;q11) & NA & 0 & NA & 88 & NA & 12 \\
\hline $17 \mathrm{P}$ & $\mathrm{F}$ & $S S X 1$ & $51, \mathrm{X}, \mathrm{t}(\mathrm{X} ; 18)(\mathrm{p} 11 ; \mathrm{q} 11),+2,+12,+15,+16,+17$ & NA & 88 & NA & 0 & NA & 12 \\
\hline $18 \mathrm{P}$ & $\mathrm{F}$ & $S S X 2$ & $\begin{array}{l}\text { 49-52,X,t(X;18)(p11;q11),del(3)(p21p22),t(6;7)(q11;p21),+8,+add(12) } \\
\text { (p12)x1-2,del(13)(q22q32),+16,+21 }\end{array}$ & NA & 0 & NA & 96 & NA & 4 \\
\hline $19 \mathrm{P}$ & $\mathrm{F}$ & $S S X 1$ & $47, \mathrm{X}, \mathrm{t}(\mathrm{X} ; 18)(\mathrm{p} 11 ; \mathrm{q} 11),+2$ & NA & 90 & NA & 0 & NA & 10 \\
\hline
\end{tabular}


1188

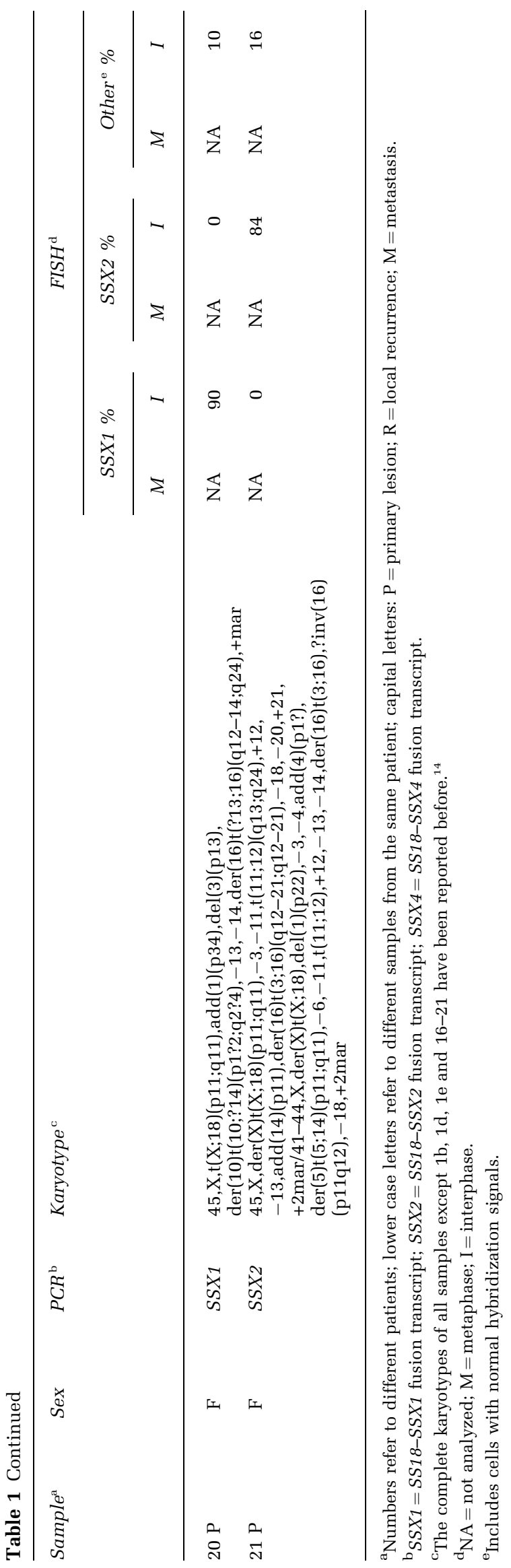

\section{Results}

In the present study, metaphase and interphase nuclei from 28 synovial sarcoma samples with known fusion gene status were analyzed with FISH probes specific for the $S S X 1, S S X 2$ and $S S 18$ loci. In all samples, the type of fusion gene was correctly identified by FISH (Table 1). At FISH, 19 samples showed a simple translocation $\mathrm{t}(\mathrm{X} ; 18)(\mathrm{p} 11.2 ; \mathrm{q} 11.2)$, with the formation of SS18-SSX1 (10 samples) or SS18-SSX2 (nine samples) fusion genes. In the samples displaying the $S S 18-S S X 1$ fusion, the distinctive features were the splitting of the $S S X 1$ (red) and $S S 18$ (green) signals into two parts and the colocalization of $S S X 1$ and $S S 18$ (red + green) signals, as observed both in metaphase and interphase cells (Figure 1b-d). In the samples with a breakpoint in $S S X 2$, the splitting of the $S S X 2$ (violet) and $S S 18$ (green) signals and the colocalization of SSX2 and SS18 (violet + green) signals were always detected (Figure 1e and f). Each case showed only one type of fusion gene and was always consistent with the results of the cytogenetic and RT-PCR studies.

Nine samples displayed variant hybridization patterns. Sample 4 was t(X;18)-negative and showed a highly complex karyotype with many unresolved aberrations at cytogenetic analysis, but it was positive for the SS18-SSX1 fusion gene by RTPCR. FISH revealed the $S S 18-S S X 1$ fusion gene in $40 \%$ of the metaphase cells, but not in interphase cells due to the high number of normal cells. Thus, a cryptic rearrangement involving the SS18 and SSX1 genes had occurred, but the chromosomal location of the fusion gene could not be determined.

Sample 5 exhibited the expected pattern of SS18SSX2 FISH signals, but in $80 \%$ of the metaphase cells the der(18) was longer than usual, suggesting a more complex translocation involving also chromosome 7 . The remaining $20 \%$ of the metaphase cells displayed an ordinary $t(X ; 18)$.

Sample 7 showed an atypical pattern of FISH signals because, in addition to the expected $S S 18-$ $S S X 2$ fusion gene on the $\operatorname{der}(\mathrm{X})$ and the $S S 18$ green signal on the normal chromosome 18, it displayed two $S S 18$ signals on two marker chromosomes and two $S S X 1$ and $S S X 2$ signals on two other markers. No colocalization of green, violet and red signals was seen, indicating the absence of a der(18).

Sample 10 was at G-banding analysis interpreted to have two copies of a $\operatorname{der}(\mathrm{X}) \mathrm{t}(\mathrm{X} ; 18)$, but no $\operatorname{der}(18) t(X ; 18)$. However, FISH experiments using centromeric and whole chromosome painting probes specific for chromosomes $\mathrm{X}$ and 18 revealed also the $\operatorname{der}(18) t(X ; 18)$ and a third chromosome carrying a part of the $\mathrm{X}$ chromosome. The colocalization of the three signals specific for the $S S 18$, SSX1 and SSX2 genes, consistent with an SSX2SS18 fusion gene, was seen on the der(18).

Sample 11 displayed a karyotype that at G-banding was interpreted to contain a balanced 


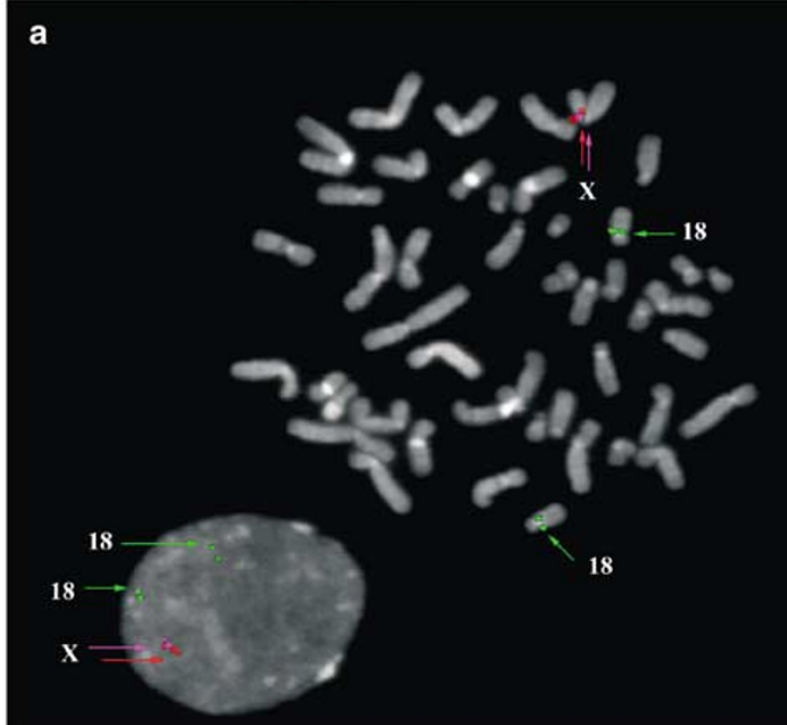

b
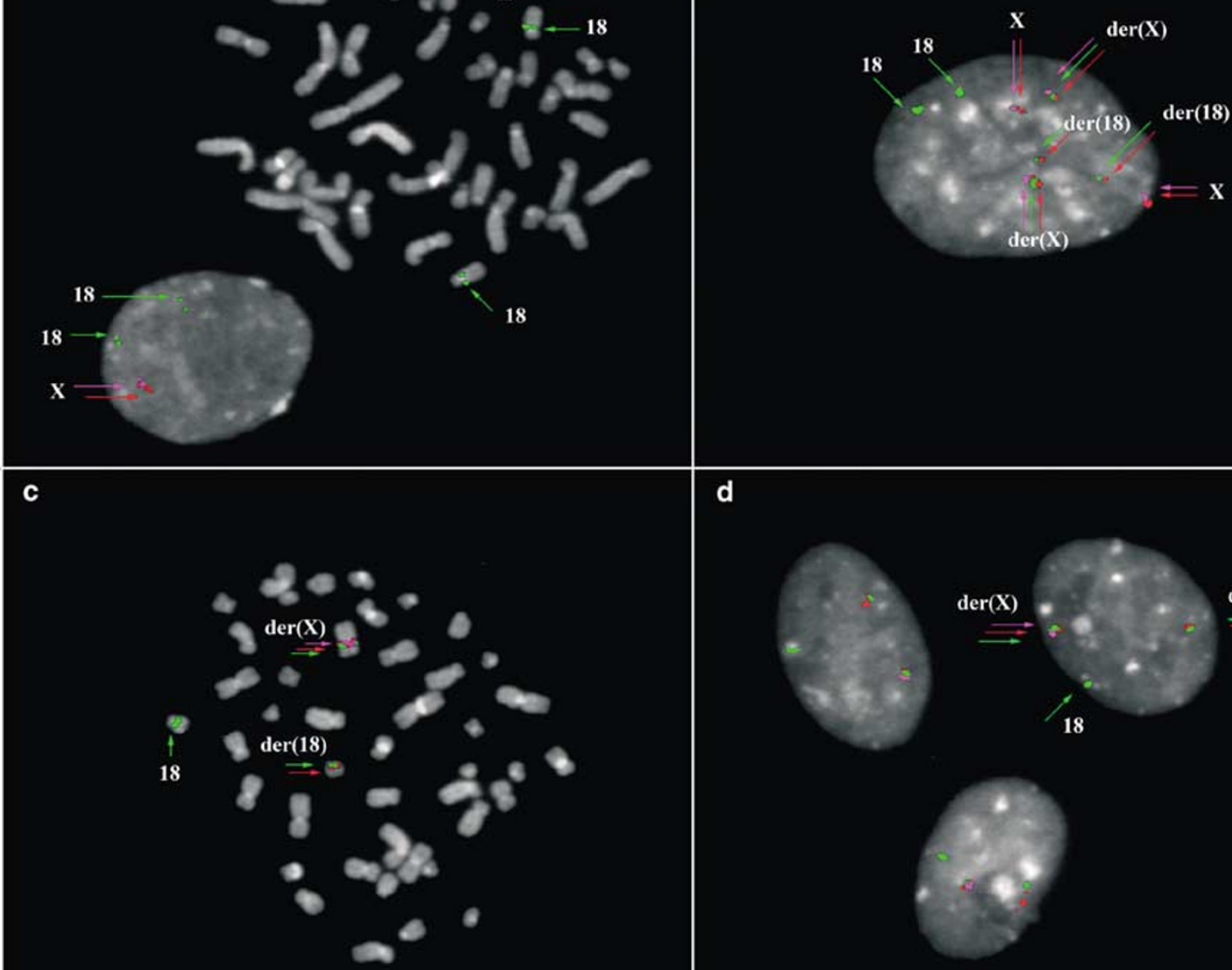

d



Figure 1 Results of some FISH experiments: SSX1 in red, SSX2 in violet, SS18 in green. (a) Pattern of FISH signals in interphase nucleus and metaphase of a normal male. (b) Distribution of signals in a tetraploid nucleus of a female (Sample 12) carrying the $t(X ; 18)$ and an SS18-SSX1 fusion gene. (c and d) Signals in metaphase and interphase nuclei of two male patients (Samples 6 and 3b) with $\mathrm{t}(\mathrm{X} ; 18)$ and the SS18-SSX1 fusion. (e and f) Signals in a metaphase cell and interphase nuclei of two different male patients (Samples 9 and 8) carrying the $\mathrm{t}(\mathrm{X} ; 18)$ and the SS18-SSX2 fusion. 


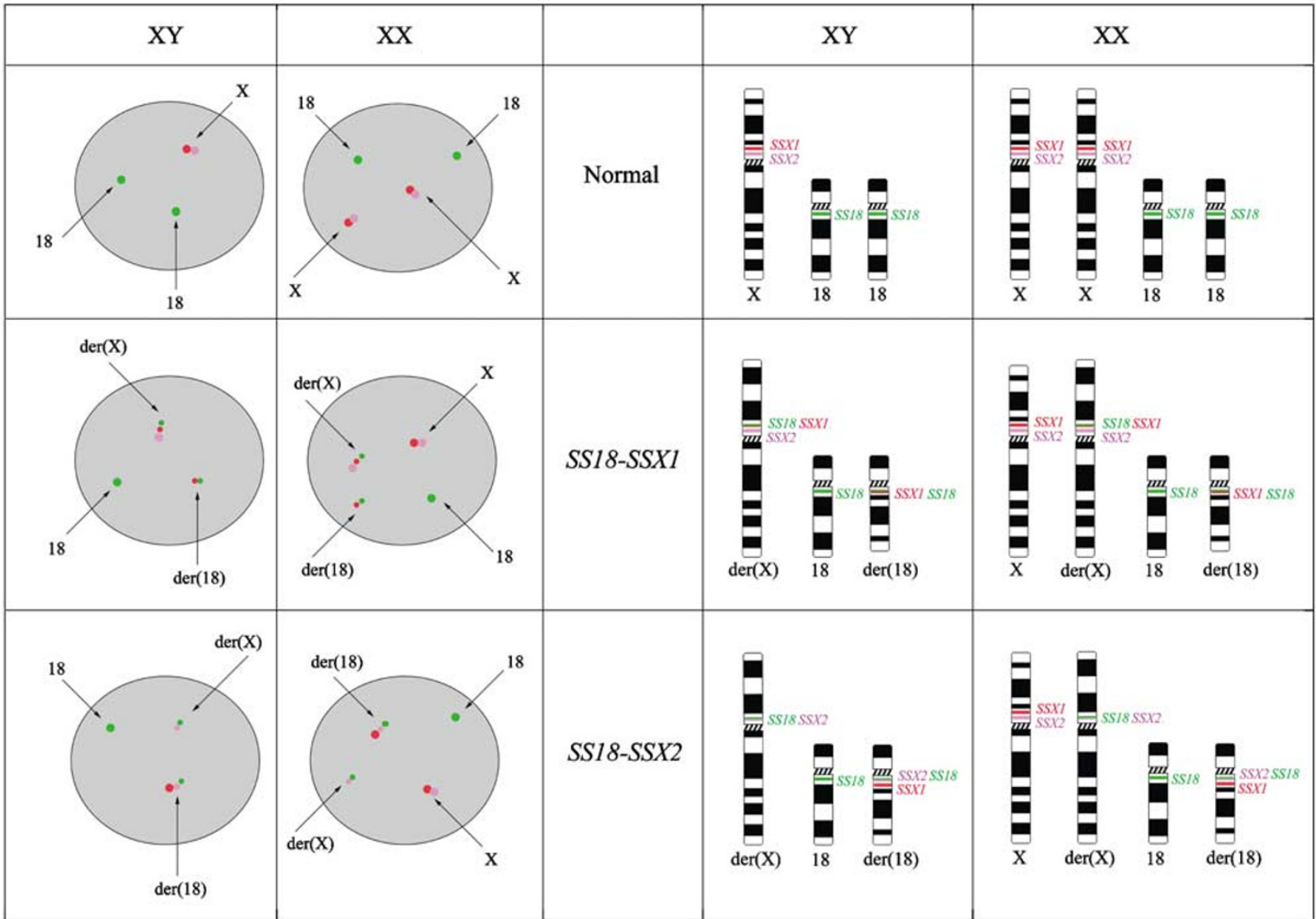

Figure 2 Schematic representation of the patterns of the expected FISH signals in normal male and female nuclei and in nuclei carrying the translocation $\mathrm{t}(\mathrm{X} ; 18)(\mathrm{p} 11.2 ; \mathrm{q} 11.2)$ (left side). Ideograms of male and female chromosomes $\mathrm{X}$ and 18, showing the localizations of the genes $S S X 1, S S X 2$ and $S S 18$ in the normal chromosomes and in rearranged ones (right side).

$\mathrm{t}(\mathrm{X} ; 18)$, and RT-PCR identified an SS18-SSX1 fusion gene. However, apart from displaying a typical der(X), FISH studies revealed a more complex rearrangement of the der(18), which exhibited a split and/or duplicated $S S 18$ signal, but no $S S X 1$ signal, and which was rearranged with a third chromosome that displayed the SSX1 signal. What was originally interpreted as the $\operatorname{der}(18) t(\mathrm{X} ; 18)$ turned out to be a der(?) consisting in most part of chromosome X material.

Sample 15, in addition to the colocalization of three signals on the der(X) and the SS18 green signal on chromosome 18, displayed the green and red signals specific for the $S S 18$ and $S S X 1$ genes on two different chromosomes. The karyotype showed a complex translocation $\mathrm{t}(\mathrm{X} ; 20 ; 8 ; 15 ; 18)$, which was in agreement with this variant pattern of FISH signals.

In samples 13, 14 and 16-21 only interphase nuclei were analyzed. In sample 13, the nuclei showed colocalization of the SS18 and SSX1 signals, but the RT-PCR results had revealed an SS18-SSX4 fusion gene. The FISH data fit with the RT-PCR results because $S S X 4$ is located close to $S S X 1$ and was included in BAC clone RP11-344N17, the most proximal clone among the three clones of the pool used for SSX1.

In sample 14 , almost $3 / 4$ of the nuclei $(72 \%)$ showed the colocalization of signals specific for the SS18 and SSX2 genes, but not the colocalization of green, violet and red signals. This is consistent with the complex translocation between the chromosomes X, 16 and 18, as shown by G-banding.

In sample 21, the signal for $S S X 2$ was split and colocalized with the signal for SS18. No signal pattern corresponding to a $\operatorname{der}(18) \mathrm{t}(\mathrm{X} ; 18)$ was seen, in agreement with the cytogenetic findings.

\section{Discussion}

In the present study, we used eight BAC clones covering the genes $S S X 1, S S X 2$ and $S S 18$ to identify the type of fusion gene (SS18-SSX1 or SS18-SSX2) in 28 synovial sarcoma samples. Since the identification of the $S S X$ and $S S 18$ genes, ${ }^{6,16}$ this is, to our knowledge, the largest series of synovial sarcoma samples screened for the type of fusion gene by FISH. Previously, FISH assays have been performed 
with whole chromosome painting, alphoid, YAC, PAC and cosmid probes, mainly with the purpose of detecting the $\mathrm{t}(\mathrm{X} ; 18)$, irrespective of the type of $S S X$ gene involved. ${ }^{17-30}$

The BAC clones that we selected allowed us not only to detect a simple $\mathrm{t}(\mathrm{X} ; 18)$, but also more complex variant translocations. In fact, at FISH analysis, only 19/28 samples displayed a simple $t(X ; 18)$, whereas the remaining nine samples showed further aberrations. The former consisted of 10 samples having the SS18-SSX1 fusion gene and nine samples with SS18-SSX2. Among the samples with more complex rearrangements, three showed the SS18-SSX1 fusion gene, five had SS18$S S X 2$ and one displayed SS18-SSX4. We never observed the presence of both SS18-SSX1 and SS18-SSX2 fusion genes in the same sample, which is in contrast to a recent publication in which RTPCR and FISH findings were interpreted to suggest the simultaneous occurrence of the two fusion genes in a subset of synovial sarcoma. ${ }^{30}$ This discrepancy could be due to chance; as only $10 \%$ of the cases reported by Yang et $a I^{30}$ were positive for both $S S 18$ $S S X 1$ and SS18-SSX2, such cases might not have been included in our series. On the other hand, synovial sarcomas expressing more than one fusion gene have not been reported by others, why artefacts from nested RT-PCR must be considered a possible explanation for this phenomenon.

In the present study, we had included one of the very rare cases of synovial sarcoma with the SS18$S S X 4$ gene. Obviously, this type of fusion could not be distinguished from the SS18-SSX1 fusion gene because the $S S X 4$ gene is included in the clone RP11-344N17, the most proximal clone in the BAC pool used for the detection of $S S X 1$ rearrangement. Since $S S X 1$ is contained in the clone RP11-552E4, the separate use of RP11-552E4 or RP11-344N17 could, theoretically, distinguish between SSX1 and $S S X 4$ rearrangements. However, bearing in mind the low frequency of SS18-SSX4 fusions, we preferred to add the RP11-344N17 clone in order to obtain strong and unequivocal split signals. Furthermore, there are so far no data indicating that patients with SS18-SSX4-positive synovial sarcoma should have a better prognosis than those with SS18-SSX1positive tumors.

In almost all the cases, the percentage of interphase cells showing SS18-SSX1 or SS18-SSX2 fusion gene by FISH was lower than in the corresponding metaphase cells. Most probably, there are several explanations for this discrepancy. First, a higher mitotic activity of the $\mathrm{t}(\mathrm{X} ; 18)$-carrying cells in vitro would lead to a relative enrichment of sarcoma cells among the dividing cells. Second, hybridization patterns are in general more difficult to interpret at the interphase level than at the metaphase level, especially in cases with complex rearrangements. Third, interphase nuclei often yield signals that are located in different planes, making them difficult to capture simultaneously in the microscope. Hence, the interpretation of FISH signals was sometimes not straightforward, especially in the samples displaying complex chromosome rearrangements. However, because the FISH assay that we set up is based on the simultaneous detection of split signals for the involved genes and their colocalization, we were able to minimize the problems in interpreting unusual hybridization patterns that may arise from, for example, polyploidization or three-way translocations. Furthermore, it should be noted that the cases that were included in our study were selected not only on the basis of their SS18-SSX fusion status, but also so that as many complex karyotypes and varieties of chromosome $\mathrm{X}$ and 18 rearrangements as possible could be analyzed. In an unselected series of synovial sarcoma, the frequency of cases with an ordinary $t(X ; 18)$ would be expected to be much higher.

Thus, apart from being a valuable tool, complementary to RT-PCR and independent on RNA degradation, in characterizing the status of the SSX and $S S 18$ genes in metaphase spreads, the results from interphase nuclei also suggest that the BAC probes can be employed in FISH studies on archived samples.

\section{Acknowledgements}

This work was supported by the Swedish Cancer Society, the Swedish Children's Cancer Foundation, AIRC (Associazione Italiana per la Ricerca sul Cancro) and CEGBA (Centro di Eccellenza Geni in campo Biosanitario e Agroalimentare). C Surace was supported by a FIRC fellowship (Fondazione Italiana per la Ricerca sul Cancro).

\section{References}

1 Fletcher CDM, Unni KK, Mertens F, (eds). World Health Organization Classification of Tumours. Pathology and Genetics of Tumours of Soft Tissue and Bone. IARC Press: Lyon, 2002.

2 Guillou L, Coindre JM, Gallagher G, et al. Detection of the synovial sarcoma translocation $\mathrm{t}(\mathrm{X} ; 18)(S Y T ; S S X)$ in paraffin-embedded tissue using reverse transcriptase-polymerase chain reaction: a reliable and powerful diagnostic tool for pathologists. Hum Pathol 2001;32:105-112.

3 Turc-Carel C, Dal Cin P, Limon J, et al. Involvement of chromosome $\mathrm{X}$ in primary cytogenetic change in human neoplasia: nonrandom translocation in synovial sarcoma. Proc Natl Acad Sci USA 1987;84: 1981-1985.

4 Sandberg AA, Bridge JA. Updates on the cytogenetics and molecular genetics of bone and soft tissue tumors. Synovial sarcoma. Cancer Genet Cytogenet 2002;133:1-23.

5 Mitelman F, Johansson B, Mertens F (eds). Mitelman Database of Chromosome Aberrations in Cancer 2004, 
(available from http://cgap.nci.nih.gov/Chromosomes/ Mitelman).

6 Clark J, Rocques PJ, Crew AJ, et al. Identification of novel genes, $S Y T$ and $S S X$, involved in the $\mathrm{t}(\mathrm{X} ; 18)(\mathrm{p} 11.2 ; \mathrm{q11.2})$ translocation found in human synovial sarcoma. Nat Genet 1994;7:502-508.

7 dos Santos NR, de Brujin DRH, Geurts van Kessel A. Molecular mechanisms underlying human synovial sarcoma development. Genes Chromosomes Cancer 2001;30:1-14.

8 Antonescu CR, Kawai A, Leung DH, et al. Strong association of SYT-SSX fusion type and morphologic epithelial differentiation in synovial sarcoma. Diagn Mol Pathol 2000;9:1-8.

9 Ladanyi M, Antonescu CR, Leung DH, et al. Impact of $S Y T-S S X$ fusion type on the clinical behaviour of synovial sarcoma: a multi-institutional retrospective study of 243 patients. Cancer Res 2002;62:135-140.

10 Skytting B, Nilsson G, Brodin B, et al. A novel fusion gene, $S Y T-S S X 4$, in synovial sarcoma. J Natl Cancer Inst 1999;91:974-975.

11 Storlazzi CT, Mertens F, Mandahl N, et al. A novel fusion gene, SS18L1-SSX1, in synovial sarcoma. Genes Chromosomes Cancer 2003;37:195-200.

12 Mandahl N, Heim S, Arheden K, et al. Three major cytogenetic subgroups can be identified among chromosomally abnormal solitary lipomas. Hum Genet 1998;79:203-208.

13 Mitelman F, (ed). An International System for Human Cytogenetic Nomenclature. S Karger: Basel, 1995.

14 Panagopoulos I, Mertens F, Isaksson M, et al. Clinical impact of molecular and cytogenetic findings in synovial sarcoma. Genes Chromosomes Cancer 2001; 31:362-372.

15 Höglund M, Johansson B, Pedersen-Bjergaard J, et al. Molecular characterization of $12 p$ abnormalities in hematologic malignancies: deletion of KIP1, rearrangement of TEL, and amplification of CCND2. Blood 1996;87:324-330.

16 Crew AJ, Clark J, Fisher C, et al. Fusion of $S Y T$ to two genes, $S S X 1$ and $S S X 2$, encoding proteins with homology to the Kruppel-associated box in human synovial sarcoma. EMBO J 1995;14:2333-2340.

17 Shipley JM, Clark J, Crew AJ, et al. The $t(X ; 18)(p 11.2 ; q 11.2)$ translocation found in human synovial sarcomas involves two distinct loci on the $\mathrm{X}$ chromosome. Oncogene 1994;9:1447-1453.

18 de Leeuw B, Suijkerbuijk RF, Olde Weghius D, et al. Distinct Xp11.2 breakpoint regions in synovial sarco- ma revealed by metaphase and interphase FISH: relationship to histologic subtypes. Cancer Genet Cytogenet 1994;73:89-94.

19 Janz M, de Leeuw B, Weghius DO, et al. Interphase cytogenetic analysis of distinct X-chromosomal translocation breakpoints in synovial sarcoma. J Pathol 1995;175:391-396.

20 Poteat HT, Corson JM, Fletcher JA. Detection of chromosome 18 rearrangement in synovial sarcoma by fluorescence in situ hybridization. Cancer Genet Cytogenet 1995;84:76-81.

21 Nagao K, Ito H, Yoshida H. Chromosomal translocation $\mathrm{t}(\mathrm{X} ; 18)$ in human synovial sarcomas analyzed by fluorescence in situ hybridization using paraffinembedded tissue. Am J Pathol 1996;148:601-609.

22 Hirakawa N, Naka T, Yamamoto I, et al. Overexpression of bcl-2 protein in synovial sarcoma: a comparative study of other soft tissue spindle cell sarcomas and an additional analysis by fluorescence in situ hybridization. Hum Pathol 1996;27:1060-1065.

23 Sozzi G, Minoletti F, Miozzo M, et al. Relevance of cytogenetic and fluorescent in situ hybridization analyses in the clinical assessment of soft tissue sarcoma. Hum Pathol 1997;28:134-142.

24 Yang $\mathrm{P}$, Hirose $\mathrm{T}$, Hasegawa $\mathrm{T}$, et al. Dual-colour fluorescence in situ hybridization analysis of synovial sarcoma. J Pathol 1998;184:7-13.

25 Geurts van Kessel A, de Bruijn D, Hermsen L, et al. Masked $t(X ; 18)(p 11 ; q 11)$ in a biphasic synovial sarcoma revealed by FISH and RT-PCR. Genes Chromosomes Cancer 1998;23:198-201.

26 Iwasaki H, Ishiguro $\mathrm{M}$, Ohjimi $\mathrm{Y}$, et al. Synovial sarcoma of the prostate with $\mathrm{t}(\mathrm{X} ; 18)(\mathrm{p} 11.2 ; \mathrm{q} 11.2)$. Am J Surg Pathol 1999;23:220-226.

27 Birdsall S, Osin P, Lu YJ, et al. Synovial sarcoma specific translocation associated with both epithelial and spindle cell components. Int J Cancer 1999;82: 605-608.

28 Debiec-Rychter M, Sciot R, Hagemeijer A. Common chromosome aberrations in the proximal type of epithelioid sarcoma. Cancer Genet Cytogenet 2000; 123:133-136.

29 Lestou VS, O’Connell JX, Robichaud M, et al. Cryptic $\mathrm{t}(\mathrm{X} ; 18)$, ins $(6 ; 18)$, and $S Y T-S S X 2$ fusion gene in a case of intraneural monophasic synovial sarcoma. Cancer Genet Cytogenet 2002;138:153-156.

30 Yang K, Lui WO, Xie Y, et al. Co-existence of SYT$S S X 1$ and $S Y T-S S X 2$ fusions in synovial sarcomas. Oncogene 2002;21:4181-4190. 